\title{
Asymmetrical Multilevel Inverter with Modified Absolute Sinusoidal PWM Technique for Sensorless Control of Induction Motor
}

\author{
Rakan Khalil ANTAR ${ }^{1}$, Emad Hussen SADIQ, Asef A. SALEH ${ }^{3}$ \\ rakan.antar@ntu.edu.iq ${ }^{1}$,emad.sadiq@dpu.edu.krd², asef.alhyali68@gmail.com³ \\ Northern Technical University, Iraq ${ }^{1,3}$, Duhok Polytechnic University, Iraq $^{2}$
}

\begin{abstract}
Sensorless speed and torque control of a three-phase induction motor utilizing cascaded H-bridge inverter with unequal selected DC voltage sources (USDCVS) is presented in this study. Several output voltages with minimum distortions and IGBTs are achieved with DC input voltage sources equal to $(1,3,9) V_{d c}$. The induction motor speed and torque are estimated depending on the instantaneous output phase voltages and currents of the drive circuit. A novel controller circuit is built depending on a modified absolute sinusoidal PWM (MASPWM) technique. Embedded s-function is coded to regenerate switching pulses and get various output levels. Simulation results demonstrate that the USDCVS of the multilevel inverter based on MASPWM technique produces different output levels with acceptable distortion. Also, show an acceptable sensorless speed and torque responses at steady-state and dynamic operation conditions under different speeds and mechanical load torques that explained the strength of the drive and control circuits.
\end{abstract}

Keywords: Modified absolute sinusoidal PWM, asymmetrical multilevel inverter, unequal DC voltage sources, sensorless speed and torque control, induction motor.

\section{Introduction}

In industrial power system applications, induction motor (IM) is widely used because of high reliability working and low maintenance and cost. Speed and torque of IM adjusts and varies according to the applications and mechanical load torque requirements which are controlled depending on system currents, voltages and frequency [1]. The power converter circuit used in general to drive IM is a rectifier-inverter type with different control strategies. $\mathrm{DC} \backslash \mathrm{AC}$ converter circuits are designing to generate AC waveforms from DC power sources. In high and medium power applications, multilevel cascaded H-bridge voltage source inverter (CHBVSI) produces higher output voltages with lower THD than the conventional type. Pulse width modulation algorithms, applications, comparisons, and experimental circuits of CHBVSI are performed in [2-6]. The multilevel CHBVSI utilizes the same DC input source per each cell of the H-bridge. To increase output levels, more IGBTs and DC voltage sources are needed. Utilizing unequal selected DC voltage sources (USDCVS), higher output levels and fewer power electronics devices achieved last years. The circuit illustrated in Fig. 1 provides higher output levels with DC sources ratio as explained in Table1 [7-9]. The structure $\left(V_{d c}, V_{d c}, V_{d c}\right)$ type provides the lowest levels. whilst $\left(V_{d c}, 3 V_{d c}, 9 V_{d c}\right)$ type produces the highest number of levels. Three CHBVSI cells produce 27-level output voltage depending on the structure $\left(V_{d c}\right.$, $3 V_{d c}, 9 V_{d c}$ ) type which is adopted and built by [10-15] applying optimization, selective harmonic 
elimination (SHE), and multi-carrier PWM techniques. The output phase voltage of multilevel voltage source inverter can be improved using different PWM techniques to get approximating sinusoidal waveform of the output voltage $[16,17]$.

In 2011 [18], a symmetry half-wave SHE PWM technique with a multilevel inverter was suggested. This technique is studied to obtain different points in a half cycle with different modulation indexes to get effective areas that give the best THD. In 2015 [19], a 7-level CHBVSI with unequal separated DC sources was used. A fuzzy logic algorithm is used to select switching angles and an artificial bee's colony (ABC) system optimises the selection of these angles. Simulation results of the output voltage illustrated that the THD using fuzzy with ABC technique gives results better than particle swarm optimization (PSO) and fuzzy-PSO. In 2016 [20], switching angles of a 27-level cascaded H-bridge inverter are selected based on genetic algorithm and particle swarm optimization methods. The THD of the output voltage is changed from $28.9 \%$ to $2.92 \%$ for the modulation index from 0.09 to 1. In 2018 [21], symmetrical (7level) and asymmetrical (9-level) inverters with less power switching devices based on sinusoidal and modified square PWM were used. The THD of the output voltage for symmetrical and asymmetrical inverter are $16.4 \%$ and $15.2 \%$, respectively. In the same year [9], 27-level inverter depending on the structure $\left(V_{d c}, 3 V_{d c}, 9 V_{d c}\right)$ was adopted. A modified absolute sinusoidal PWM (MASPWM) method is designed and built to control the system under stable and dynamic conditions for various output levels. The THD with no 0V step level is less than including $0 \mathrm{~V}$ step. The phase voltage and current distortions are between $0.085 \%$ and $1.16 \%$. In 2019 [22], a single-phase seven-level VSI using seven power electronics switching devices was used and tested for the grid-tied application. A model predictive control is used to get a sinusoidal waveform during changing the grid current amplitude and power factor. Modeling and practical results illustrate that THD of the injected current is $1.23 \%$.

In this paper, the equal voltage DC sources of the CHBVSI cells replace with the USDCVS depending on the structure $\left(V_{d c}, 3 V_{d c}, 9 V_{d c}\right)$ to increase output voltage levels as shown in Fig.2. The power circuit is used to drive and control speed and torque of an IM without sensors as illustrated in Fig.2. The IM speed and torque are estimated depending on the instantaneous output phase voltages and currents of the drive circuit. The controller system is built and modeled depending on the MASPWM technique as illustrated in Fig.3 [9]. Therefore, the novelty of the proposed system is to improve the power quality of the 27-level CHBVSI with USDCVS depending on MASPWM technique to drive and sensorless control of the induction motor.

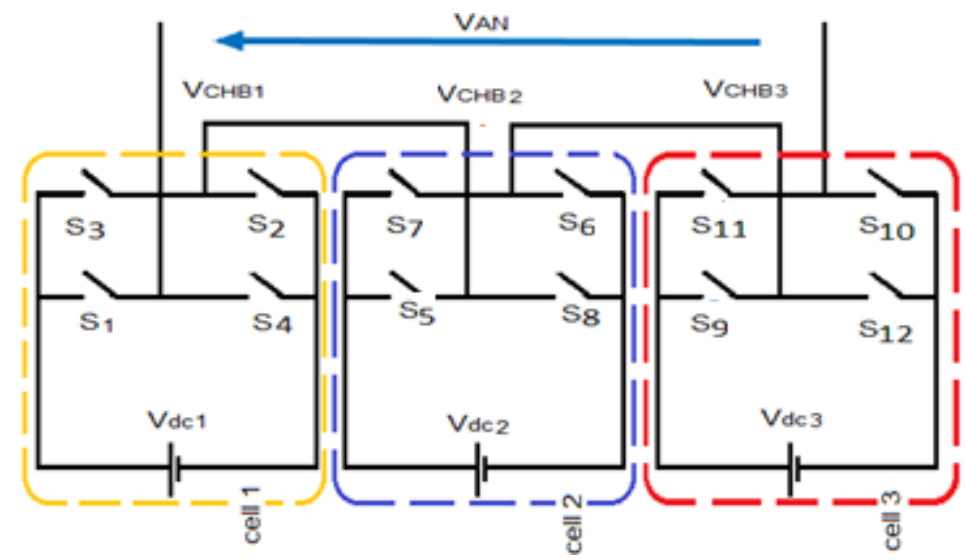

Fig. 1. Three CHBVSI cells. 
Table 1. Arrangement between DC input sources and output levels.

\begin{tabular}{|c|c|c|c|c|c|c|c|c|c|c|c|c|c|c|c|c|c|c|}
\hline $\mathbf{V}_{\mathbf{C H B} 1} / \mathbf{V}_{\mathbf{d c}}$ & \multicolumn{18}{|c|}{1} \\
\hline $\mathbf{V}_{\mathbf{C H B} 2} / \mathbf{V}_{\mathbf{d c}}$ & \multicolumn{5}{|c|}{1} & \multicolumn{6}{|c|}{2} & \multicolumn{7}{|c|}{3} \\
\hline $\mathbf{V}_{\mathbf{C H B}} / \mathbf{V}_{\mathbf{d c}}$ & 1 & 2 & 3 & 4 & 5 & 2 & 3 & 4 & 5 & 6 & 7 & 3 & 4 & 5 & 6 & 7 & 8 & 9 \\
\hline $\begin{array}{c}\mathrm{V}_{\text {AN }} \\
\text { (level) }\end{array}$ & 7 & 9 & 11 & 13 & 15 & 11 & 13 & 15 & 17 & 19 & 21 & 15 & 17 & 19 & 21 & 23 & 25 & 27 \\
\hline
\end{tabular}

\section{Modified Absolute Sinusoidal PWM Strategy}

Different PWM algorithms such as space vector modulation, frequency type modulation, SHE technique, and multi-carrier PWM algorithm are used with multilevel inverters. Multicarrier signals based on disposition, phase and level shift methods are used to generate PWM pulses [23]. In this study, one carrier (triangular) signal is used and compared with the reference signal, which is a modified absolute sinusoidal signal. The MASPWM controller algorithm produces a reference signal (absolute sinusoidal signal ASS) with magnitude represents the desired output voltage level. The block shown in Fig.3 detects and creates positive and negative signals from the reference sine signal. The ASS is converted to a number of discrete levels to get the absolute sinusoidal discrete signal or quantization sequence, which is a sequence of DC voltages with amplitudes that tracks sine wave function values at discrete times. The modified ASS is the difference between the ASS and quantization sequence signal as shown in Fig.4. The MASPWM signal of the power drive circuit produces by comparing one triangular signal with modified ASS. Embedded MATLAB s-function is coded based on the state conditions presented in Table 2 to regenerate and apportion PWM pulses of the proposed CHBVSI and choose ONOFF state of the power electronics devices. The MASPWM controller is built to generate various levels in the output voltages based on the DC input source arrangements. Therefore, thirteen levels appear in the output of the proposed power circuit as explained in Table 2.

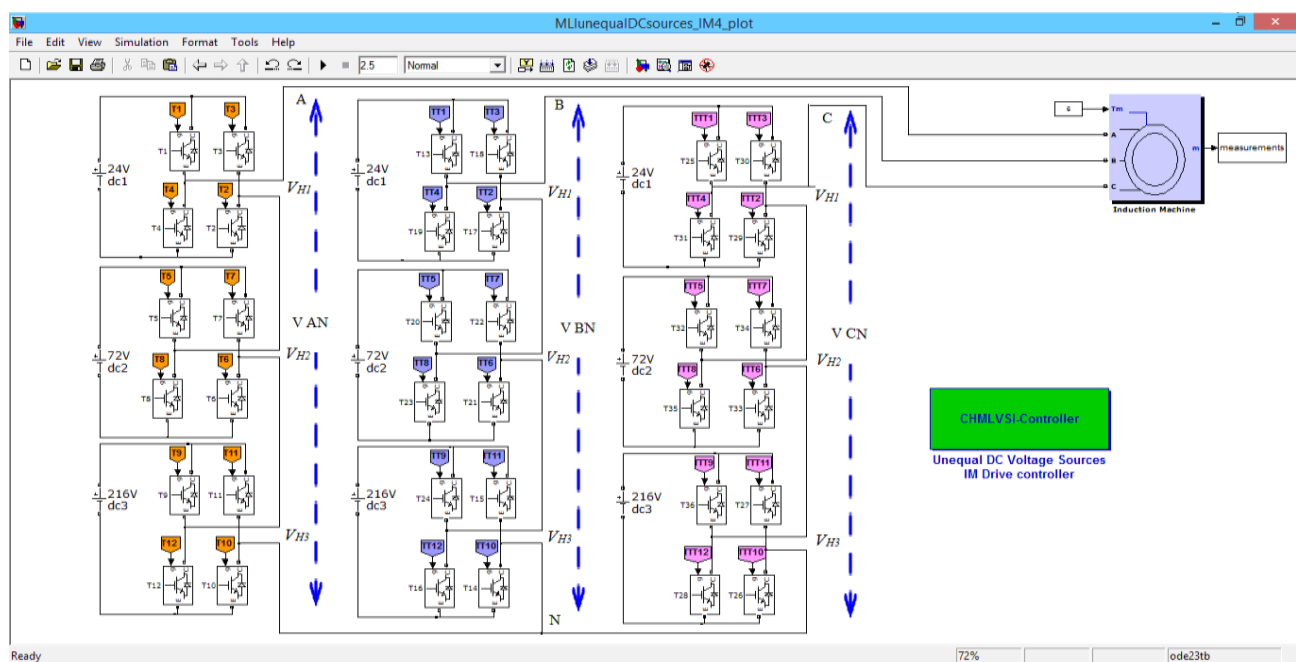

Fig. 2. MATLAB model of three-phase Induction Motor Drive circuit. 


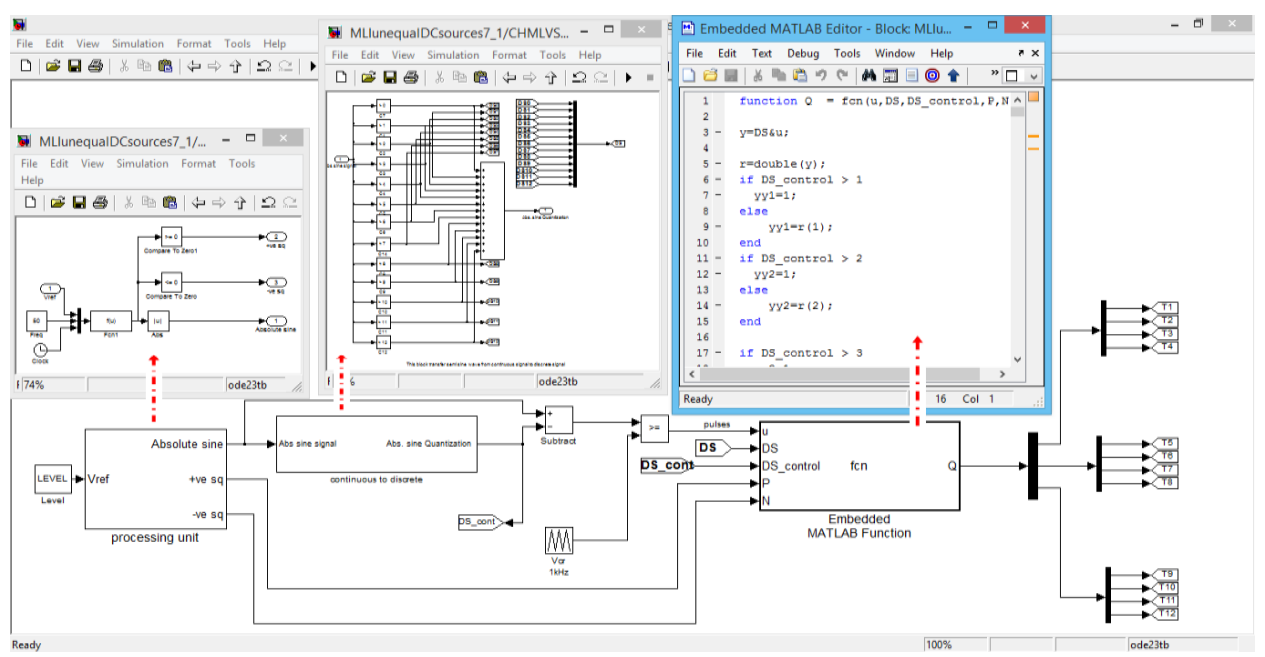

Fig. 3. Controller model of the 27-level CHBVSI based on the MASPWM algorithm.

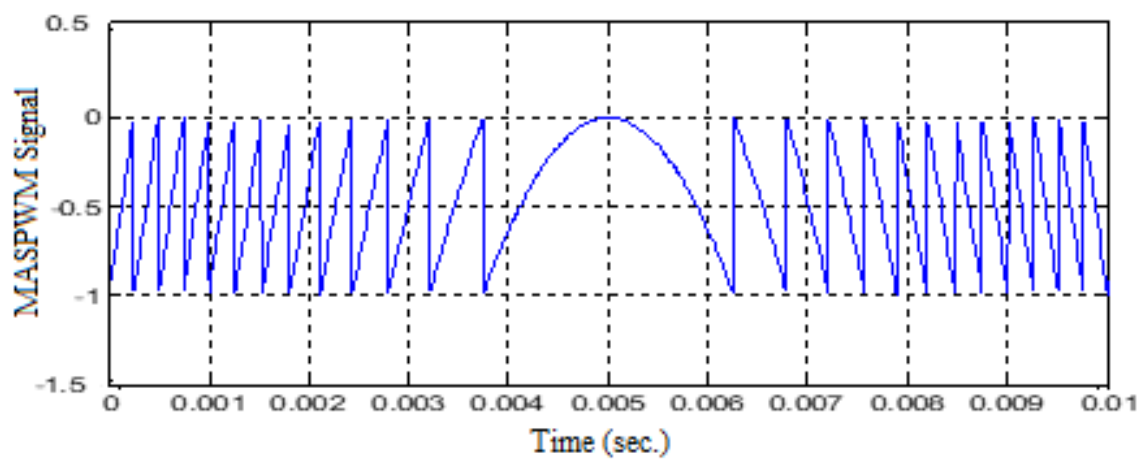

Fig. 4. MASPWM signal

Table 2. Switches states of the proposed power circuit.

\begin{tabular}{|c|c|c|c|c|c|c|c|c|c|c|c|c|c|}
\hline $\begin{array}{c}\mathbf{V}_{\text {AN }} \\
(\mathbf{l e v e l s})\end{array}$ & $\mathbf{1}$ & $\mathbf{2}$ & $\mathbf{3}$ & $\mathbf{4}$ & $\mathbf{5}$ & $\mathbf{6}$ & $\mathbf{7}$ & $\mathbf{8}$ & $\mathbf{9}$ & $\mathbf{1 0}$ & $\mathbf{1 1}$ & $\mathbf{1 2}$ & $\mathbf{1 3}$ \\
\hline $\mathbf{T 1}$ & ON & OFF & OFF & ON & OFF & OFF & ON & OFF & OFF & ON & OFF & ON & ON \\
\hline T2 & ON & OFF & ON & ON & OFF & ON & ON & OFF & ON & ON & OFF & OFF & ON \\
\hline T3 & OFF & ON & OFF & OFF & ON & OFF & OFF & ON & OFF & OFF & ON & ON & OFF \\
\hline T4 & OFF & ON & ON & OFF & ON & ON & OFF & ON & ON & OFF & ON & OFF & OFF \\
\hline T5 & OFF & ON & ON & ON & OFF & OFF & OFF & OFF & OFF & ON & ON & ON & ON \\
\hline T6 & ON & ON & ON & ON & OFF & OFF & OFF & ON & ON & OFF & ON & ON & ON \\
\hline T7 & OFF & OFF & OFF & OFF & ON & ON & ON & OFF & OFF & ON & OFF & OFF & OFF \\
\hline T8 & ON & OFF & OFF & OFF & ON & ON & ON & ON & ON & OFF & OFF & OFF & OFF \\
\hline T9 & OFF & OFF & OFF & OFF & ON & ON & ON & ON & ON & ON & ON & ON & ON \\
\hline T10 & ON & ON & ON & ON & ON & ON & ON & ON & ON & ON & ON & ON & ON \\
\hline T11 & OFF & OFF & OFF & OFF & OFF & OFF & OFF & OFF & OFF & OFF & OFF & OFF & OFF \\
\hline T12 & ON & ON & ON & ON & OFF & OFF & OFF & OFF & OFF & OFF & OFF & OFF & OFF \\
\hline
\end{tabular}




\section{Sensorless Speed and Torque Model Circuit and Controller}

To estimate the speed of the IM, slip (wsl) and synchronous (we) speeds are computed and estimated in this paper depending on the instantaneous three-phase output phase voltages and currents [24]. The voltages and currents of the multilevel CHBVSI transform to dq-stationary frame voltages and currents components. The differences between the (wsl) and (we) waveforms produce the estimated speed (west) as illustrated in Fig.5. The electromagnetic torque (Te) is estimated (Teest) depending on the dq-stationary flux and current as explained in Fig.5 [24-25].

An artificial neural network (ANN) is a proficient tool to represent a complicated relationship between inputs and outputs. In this paper, ANN is trained to select the number of output voltage levels of the multilevel CHBVSI with USDCVS as shown in Fig.5. The proportional-integral (PI) controller is employed to adjust the number of levels to accurate the estimated speed and torque as best as possible with the required speed at the required load torque.

\section{Simulation Results}

The multilevel CHBVSI is designed and modified to produce levels higher than conventional type using USDCVS. The DC input source value is chosen equal to $24 \mathrm{~V}$. To approve the strength of the proposed power converter circuit to produce output voltages with minimum THD, simulation model results of the output phase voltages with spectrum analyser at fifteen and twenty-seven levels of the CHBVSI during no load (without IM) are illustarted in Fig.6 and Fig.7. The spectrum analyser confirmed that the low harmonic order values are approximately zero with a very small value of the higher orders. The THD of the output phase voltages with different voltage levels is illustrated in Fig.8. These results explained that the THD values are within standard limits depending on the MASPWM technique. The designed power and sensorless control circuits are used to drive the IM at a different speed and load torque conditions. The speed and electromagnetic torque responses of the IM at load torque equal to 10N.m and 12N.m are shown in Fig.9 and Fig.10. The estimate and actual speed has good responses and arrive at the desired value within 0.42 and 0.36 seconds, respectively. Figure 11 shows the three-phase output phase and line voltages and currents of the IM drive system at mechanical load torque $12 \mathrm{~N} . \mathrm{m}$. The success of the system controller's capability to drive IM at a constant speed and different load torque also at different speed values with constant load torque are illustrated in Fig.12 and Fig.13. The speed responses continue around the reference values with a steady-state error approximately zero. In order to prove the strength of the designed power circuit and controller to drive the IM at different speeds and mechanical load torques at the same time, estimated speed and torque follows the actual value and offers good responses as illustrated in Fig.14. The estimated electromagnetic torque response explains changing in the load torque. 

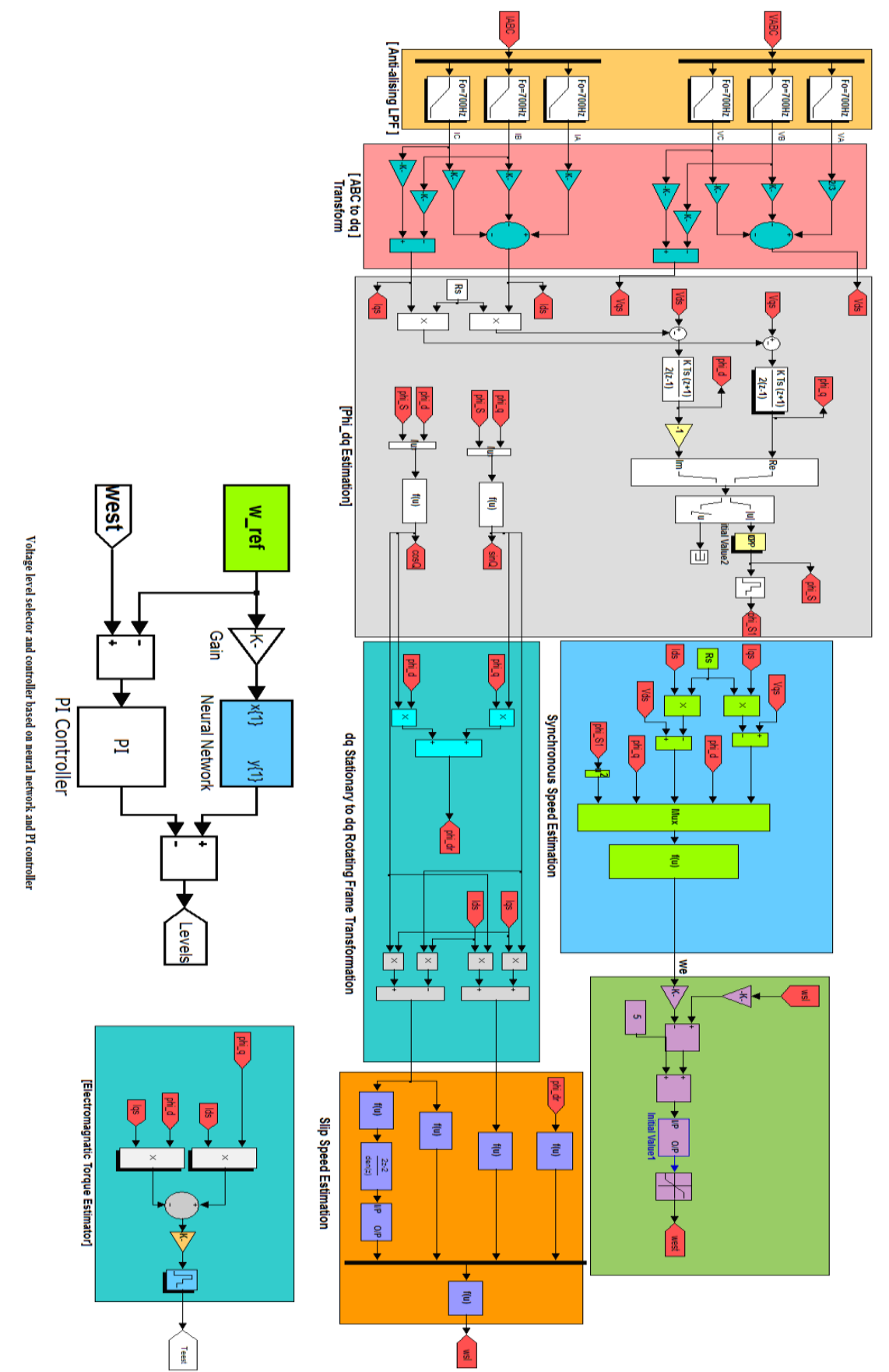

Fig. 5. Estimation model blocks of the induction motor speed and torque with voltage level selector and controller based on neural network and PI controller. 


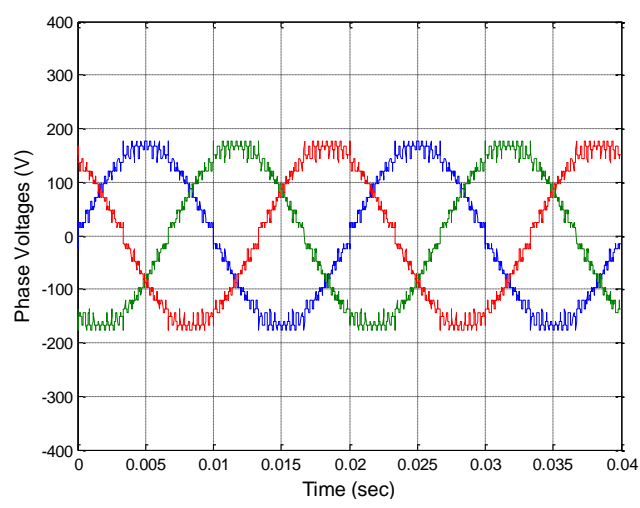

(a)

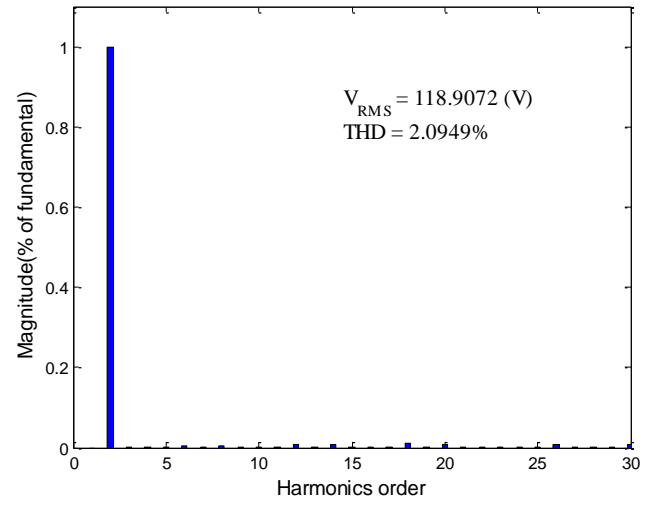

(b)

Fig.6. (a) output phase voltage and (b) its spectrum analyzer at no load condition and 15-level.

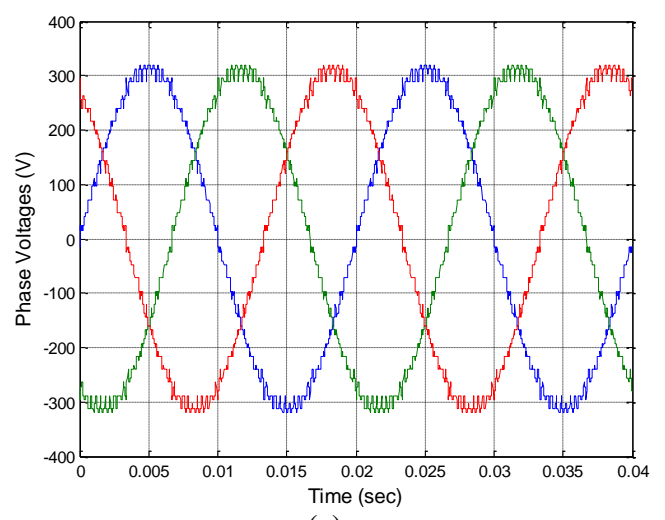

(a)

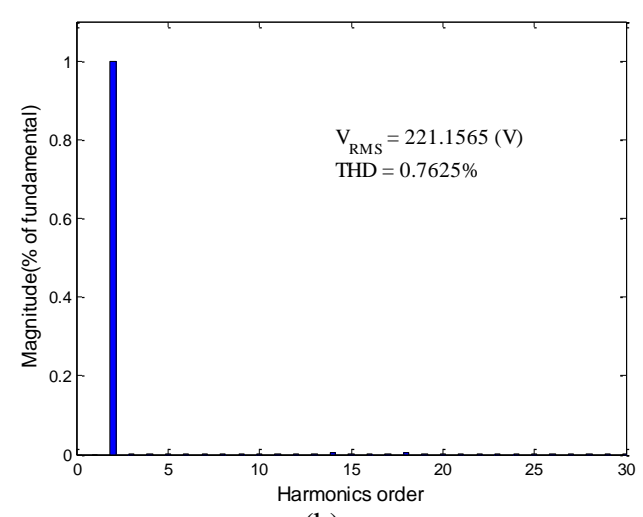

(b)

Fig.7. (a) output phase voltage and (b) its spectrum analyzer at no-load condition and 27-level 


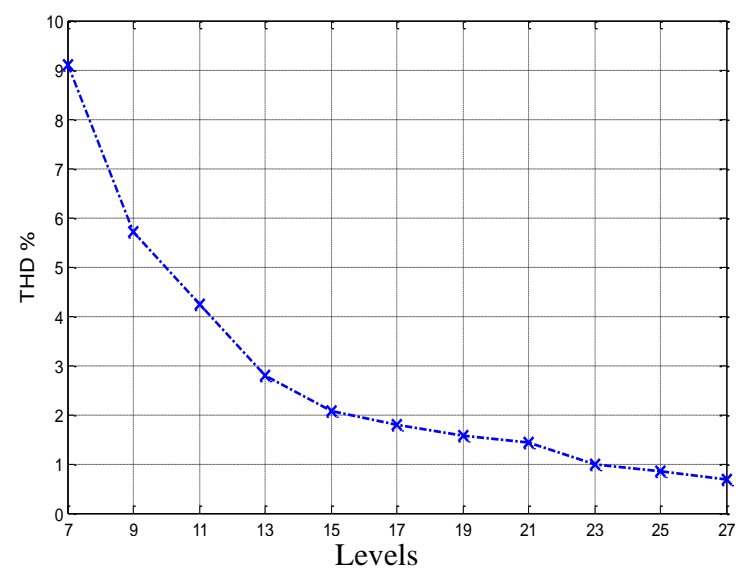

Fig. 8 THD of the output phase voltages with respect to voltage levels at no-load conditions.

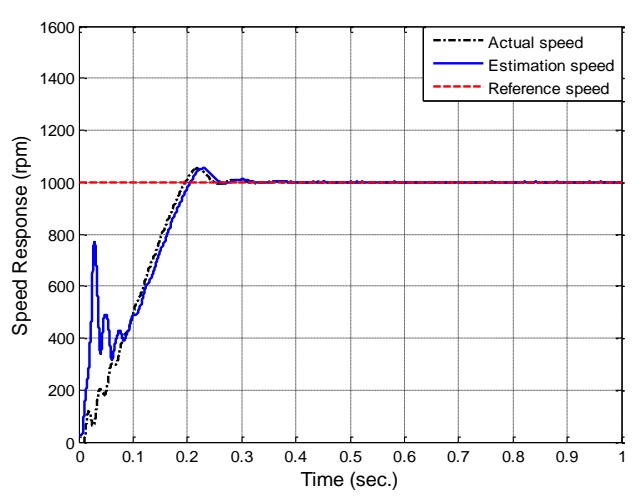

(a)

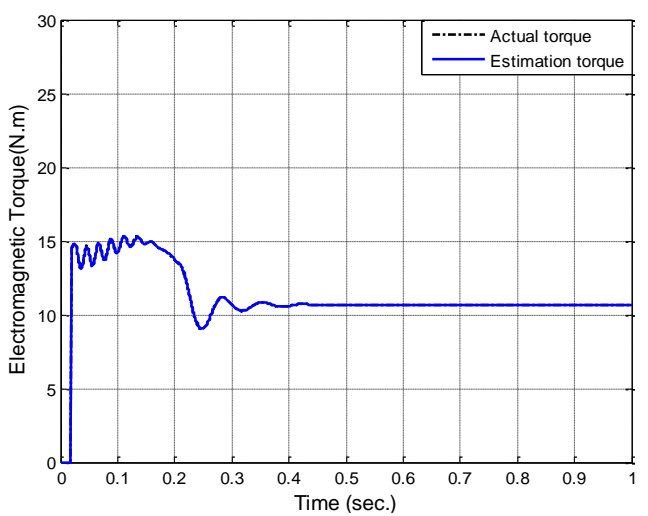

(b)

Fig.9 (a) speed and (b) electromagnetic torque responses at load torque 10N.m.

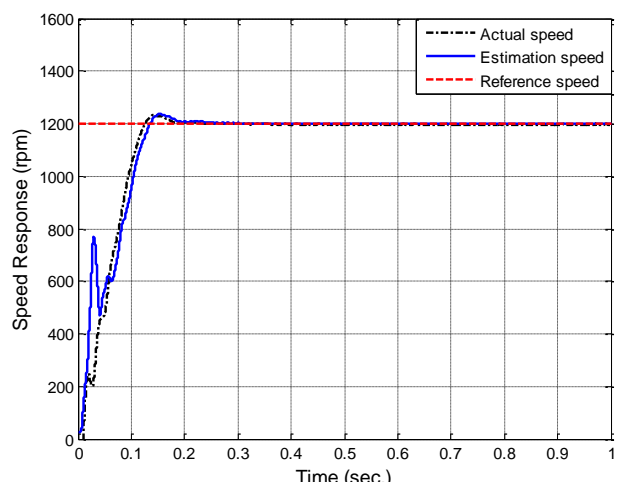

(a)

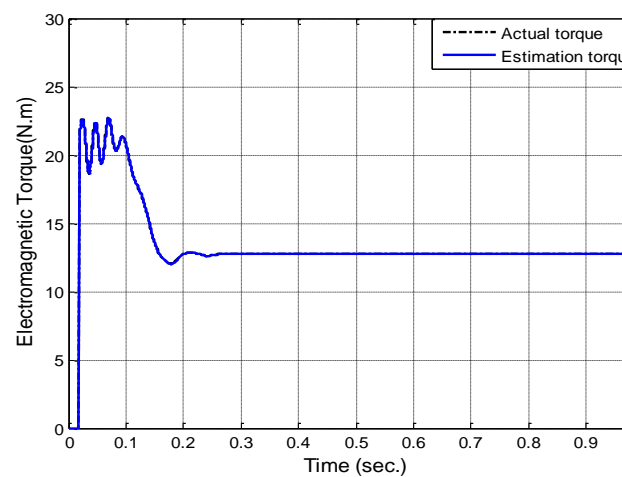

(b)

Fig.10 (a) speed and electromagnetic torque responses at load torque 12N.m. 


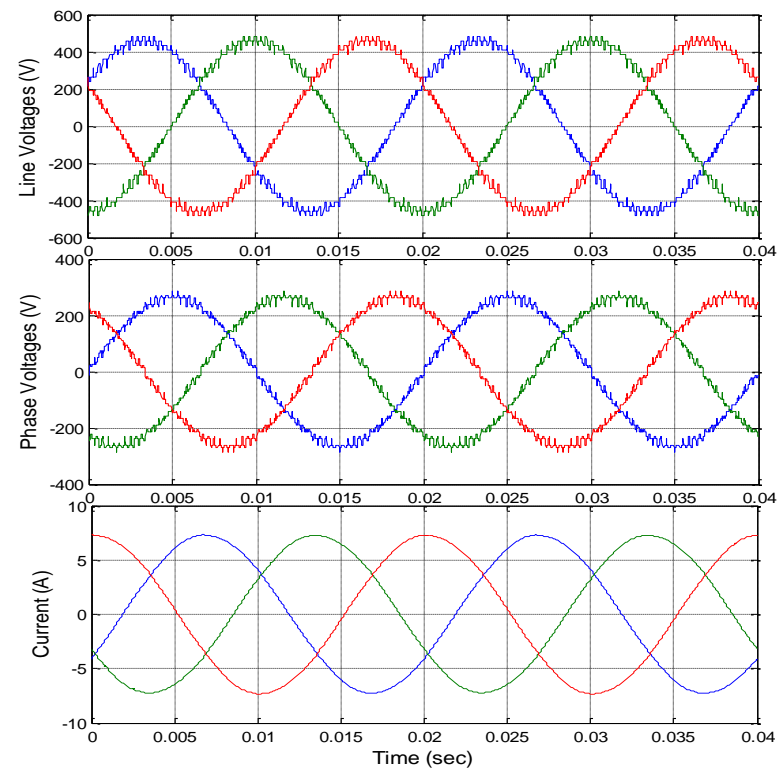

Fig. 11 Three-phase output phase and line voltages and current waveforms at 1200rpm and 12N.m.
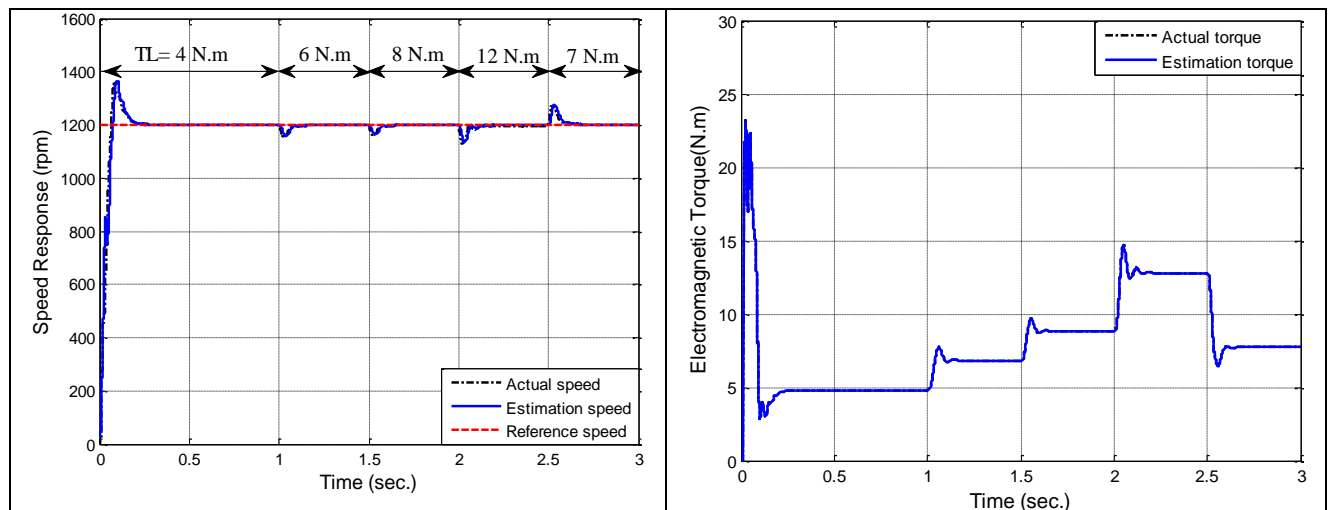

(b)

(a)

Fig. 12 system response at (a) constant speed (1200rpm) and different load torques 


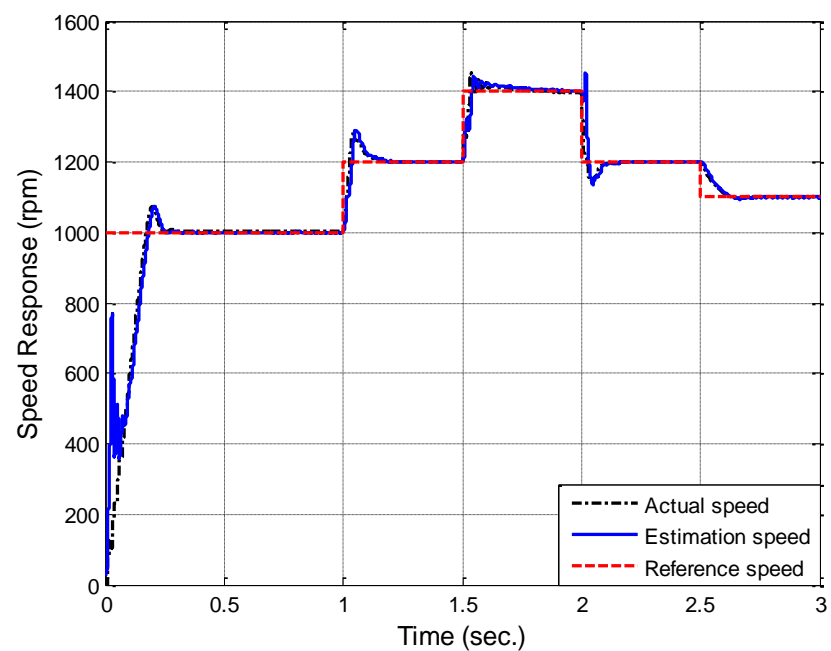

(a)

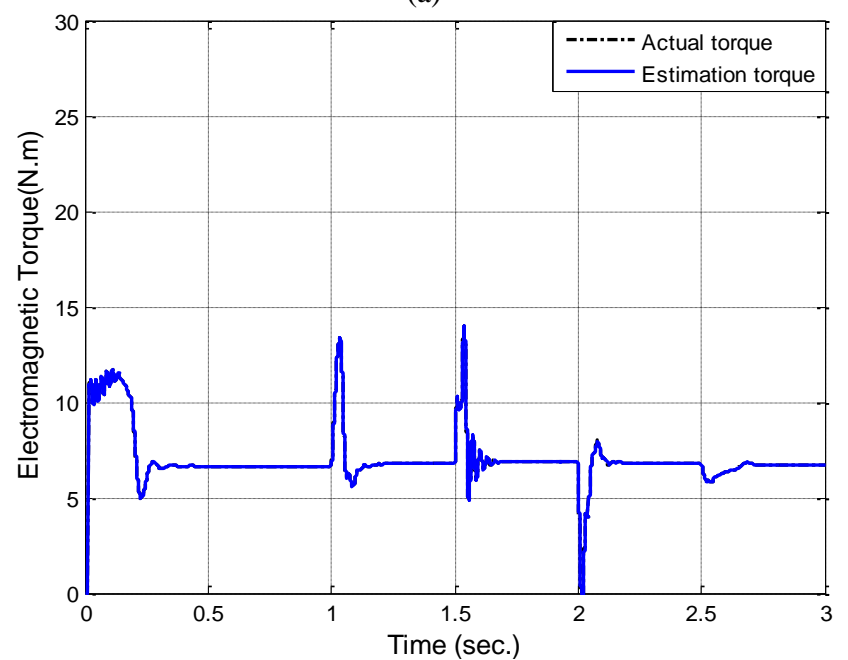

(b)

Fig. 13 system response at different speeds and constant load torque 6N.m. 


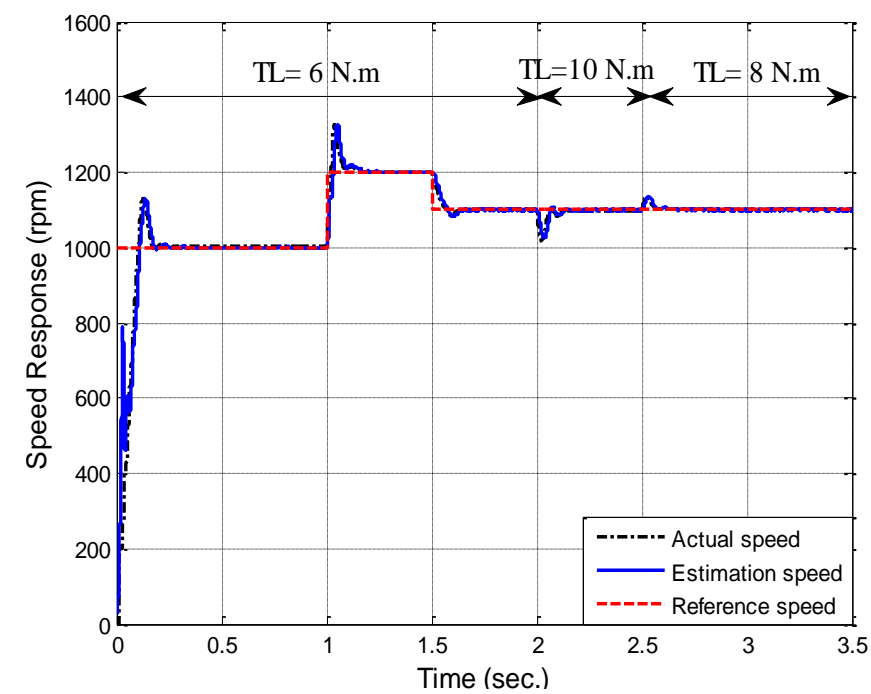

(a)

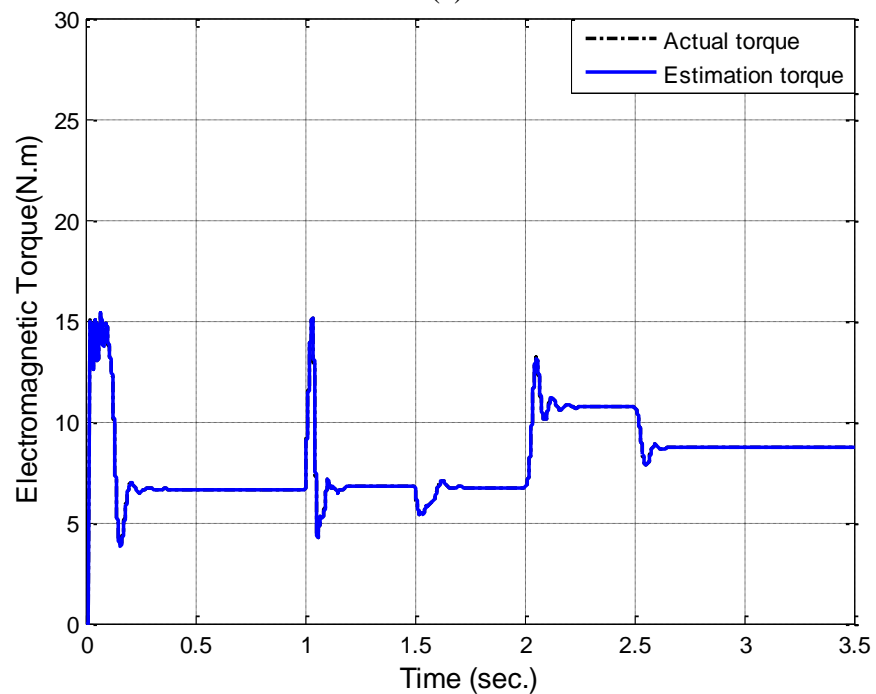

(b)

Fig. 14 Speed and torque responses at different values of speed and load torque.

\section{Conclusions}

A three-phase multilevel CHBVSI with USDCVS depending on MASPWM technique has been implemented in this study to drive an IM. The designed power circuit uses three H-bridge inverter cells in a cascaded with USDCVS to get output voltages with 27-level compared with the conventional type with 7-level. Sensorless speed and electromagnetic torque control of the IM in steady-state and dynamic operation conditions at a different speed and load torque has been done. The IM speed and electromagnetic torque are estimated depending on the output phase voltages and currents of the drive circuit. Simulation model results demonstrated that THD of the multilevel CHBVSI voltages and currents has been reduced to a minimum value 
and given acceptable power quality at different voltage levels. Also, the THD value with no 0V step level is lower than with $0 \mathrm{~V}$ step. As well as, the senseless speed and electromagnetic torque have high-quality responses at variable speeds and load torques compared with the actual value. These results support the ability of the power circuit depending on MASPWM technique and sensorless controller to drive and track the required speed and torque with the best power quality.

\section{References}

[1] N. Gurle, T. Sheikh, A. Kumari and R. Argelwar,: Speed Control of Three Phase Induction Motor by Stator Voltage Control., Journal of Network Communications and Emerging Technologies (JNCET), Vol. 6, Issue 4 (2016)

[2] Y. R. Manjunatha and B.A. Anand,: Multilevel DC Link Inverter with Reduced Switches and Batteries, International Journal of Power Electronics and Drive System (IJPEDS), Vol.4, No.3, pp. 299307 (2014)

[3] M. Soltani, M. H. khanzade and A. shoulaie,: Combined PWM Technique for Asymmetric Cascaded H-Bridge Multilevel Inverter, International Journal of Modern Engineering Research (IJMER), Vol.5, No.8, pp. 17-26 (2015)

[4] D.Shanmugavel1 and K.Ramani,: Harmonic Minimized of Cascaded H-Bridge Multilevel Inverter Using PV system, International Journal of Emerging Technology and Advanced Engineering, Vol.1, No.1, pp.1-10 (2014)

[5] P. Arora and B. Modi,: Matlab Simulation of Cascaded H-Bridge Inverter with Unequal DC Voltages, International Journal of Research in Advent Technology, Vol.2, No.6, pp. 1 - 4 (2014)

[6] A. Maheswari and I. Gnanambal,: Harmonic Analysis of Cascaded H-bridge Seven Level Inverter for RL Load Applications, Asian Power Electronics Journal, Vol.6, No.2, pp. 13-18 (2012)

[7] T. Prathiba and P. Renuga,: Performance Analysis of Symmetrical and Asymmetrical Cascaded HBridge Inverter, Journal of Electrical Engineering, pages: 1-7 (2013)

[8] A.S. Modagi and H.V. G. Raju,: Cascaded H-Bridge Multilevel Inverter with Unequal DC Sources", Journal of Electrical and Electronics Engineering (IJRDO), Vol.1, No.4, pp. 9-18 (2016)

[9] R. K. ANTAR,: Multilevel Inverter with Unequal and Selected DC Voltage Sources Using Modified Absolute Sinusoidal PWM Technique, 1st International Scientific Conference of Engineering Sciences3rd Scientific Conference of Engineering Science, IEEE, pp: 62-67 (2018)

[10] T. D. Raj and N. K. Nair,: Implementation of Cascaded H-Bridge Multi Level Inverter," MiddleEast Journal of Scientific Research, Vol.24, No.9, pp. 2752-2759 (2016)

[11] P. Kiruthika and R. Kannan,: Multi-Carrier based 27-level Hybrid Multi-level Inverter Interface with PhotoVoltaic," Indonesian Journal of Electrical Engineering, TELKOMNIKA, Vol.13, No.3, pp. 467-475 (2015)

[12] S. Singh, M. Jain and A. Singh,: Performance Evaluation of Asymmetrical Cascaded H-Bridge Multilevel Inverter, International Journal of Advanced Research in Electrical, Electronics and Instrumentation Engineering, Vol.4, Issue 1 (2015)

[13] K.Ramani and A.Krishnan,: New Hybrid 27 Level Multilevel Inverter fed Induction Motor Drive," International Journal of Recent Trends in Engineering, Vol.2, No.5 (2009)

[14] T. Azad and H R Ramesh,: A New Hybrid 27 Level Single Phase Multi Level Inverter for Induction Motor Loads, International Journal of Advanced Research in Electrical, Electronics and Instrumentation Engineering, Vol.5, Issue 5 (2016)

[15] T. Vasanthakumar and R. Nafeena,: The 27 level cascaded H-Bridge multilevel inverter using neural network and particle swarm optimization, International Conf. on Emerging Engineering Trends and Science (ICEETS), pp. 32-39 (2016)

[16] M.R. Banaei, M.R.J. Oskuee, F.M. Kazemi,: Series H-bridge with stacked multicell inverter to quadruplicate voltage levels, IET Power Electronics, Vol. 6, No. 5, pp. 878-884 (2013)

[17] S. Das, G. Narayanan, M. Pandey,: Space-vector-based hybrid pulsewidth modulation techniques for a three-level inverter, IEEE transactions on power electronics, Vol. 29, No. 9, pp.4580-4591 (2014) 
[18] W. Fei, B. Wu, and Y. Huang,: Half-wave symmetry selective harmonic elimination method for multilevel voltage source inverters, IET Power Electronics, Vol. 4, pp.335-342 (2011)

[19] M. Malarvizhi and I. Gnanambal,: Harmonics elimination in multilevel inverter with unequal DC sources by fuzzy-ABC algorithm, Journal of Experimental \& Theoretical Artificial Intelligence, Vol.27, Issue 3, pp. 273-292 (2015)

[20] A. A. K. Arani, J. S. Moghani, A. Khoshsaadat, G.B. Gharehpetian,: THD Minimization of the Output Voltage for Asymmetrical 27-Level Inverter using GA and PSO Methods, Iranian Journal of Electrical \& Electronic Engineering, Vol. 12, No. 2, pp.126-133 (2016)

[21] M. H. Yatim, A. Ponniran, M. A. Zaini, M. S. Shaili, N. A. S. Ngamidun, A. N. Kasiran, A. A. Bakar, J. N. Jumadril,: Symmetrical and Asymmetrical Multilevel Inverter Structures with Reduced Number of Switching Devices, Indonesian Journal of Electrical Engineering and Computer Science, Vol.11, No.1, pp. 144-151 (2018)

[22] C.E.S. Feloups, E.E.M. Mohamed,: A Novel Reduced Components Model Predictive Controlled Multilevel Inverter for Grid-Tied Applications, Advances in Electrical and Electronic Engineering, Vol.17, No. 3 (2019)

[23] L. A.M. Alsaqal, A.M.T.I. Alnaib, O. T. Mahmood,: Comparison of multiple modulation techniques for various topologies of multilevel converters for single phase AC motor drive, International Journal of Power Electronics and Drive System, Vol. 10, No. 2, pp. 662-671 (2019)

[24] B.K. Bose,: Power Electronics and Motor Drives, Advances and Trends. Academic Press, Elsevier Inc. (2006)

[25] J. Vedrana, S. Zeljko and V. Zdravko,: Optimal Control of Induction Motor Using High Performance Frequency Converter", 13th International Power Electronics and Motion Control Conf. (EPE-PEMC), IEEE, pp: 705-709 (2008) 